\title{
Impact of Duration of Smoking on Lung Function Parameters in Young Adult Males
}

\author{
Chandrashekhar D.M. ${ }^{1}$, Anandkumar' ${ }^{1}$, Jayalakshmi M.K. ${ }^{2}$, Prashanth Babu ${ }^{3}$ \\ ${ }^{1}$ Assistant Professor, ${ }^{2}$ Professor, ${ }^{3}$ Associate Professor, Department of Physiology, \\ Gadag Institute of Medical Sciences, Gadag, Karnataka, India
}

\begin{abstract}
Background: The tobacco epidemic is one of the biggest public health threats the world has ever faced, killing more than 8 million people a year. In 2002, about $20 \%$ of young teens smoked worldwide, half of those who begin smoking in adolescent years are projected to go on to smoke for 15 to 20 years. Smoking increases the risk of developing coronary artery disease, stroke, chronic obstructive pulmonary disease (COPD) and various malignancies. Smoking is being recognized as the most important causative factor for COPD. While studies have shown an overall 'dose response curve" for smoking and lung function, some individuals develop severe disease within few years of smoking, whereas some individuals show minimal to no clinical symptoms even after many years of smoking. Hence the following cross sectional study was undertaken to assess the extent of decline in lung function parameters with duration of smoking in young adults with no apparent clinical features of COPD.
\end{abstract}

Objectives: To assess the impact of duration of smoking on various lung function parameters in young adult males.

Materials and Method: Fifty apparently healthy, young smokers were selected for the study. Pulmonary function test was evaluated by computerized spirometer (UNI-EM SPIROMIN). Correlation between duration of smoking and various lung function parameters was analyzed by ANNOVA.

Results: All parameters were found to decline with duration of smoking, however the decline in FVC and FEV1 were statistically significant.

Conclusion: Duration of smoking is correlated strongly with decline in FVC and FEV1 values.

Keywords: Duration of Smoking, FVC, FEV1 FEV1/FVC, FEF $25-75 \%$, PEFR.

\section{Introduction}

Tobacco smoking is one of the greatest public health threats of the industrial era, accounting to more than 8 million deaths per year. There has been a sharp increase in the number of smokers globally, from 721

\section{Corresponding Author.}

Anandkumar

Assistant Professor, Department of Physiology, Gadag

Institute of Medical Sciences, Gadag, Karnataka, India e-mail: dranandhugar01@gmail.com

Ph: 8971282391 million smokers in 1980 to 967 million smokers in 2012 . In 2002 , about $20 \%$ of young teens smoked worldwide, half of these teenagers continue to smoke well into their adulthood. ${ }^{1}$

Smoking increases the risk of developing a wide range of diseases, many of which being fatal. The leading cause of death in chronic smokers is malignancy of the lung, followed by respiratory disorder (mainly COPD) and lastly cardiovascular diseases. Smoking is also an important risk factor for stroke, blindness, deafness, back pain, osteoporosis and peripheral artery disease. After the age of 40, smokers on an average have higher risk for pain and disability than non-smokers. ${ }^{2}$ 
Chronic obstructive pulmonary disease (COPD) is being recognized as the major cause for morbidity and mortality among smokers. ${ }^{3}$

Cigarette smoking is the most commonly encountered tobacco-related risk factor for COPD, the other factors like smoking tobacco in different forms like bidi, cigar, chillum, which is popular in some countries is also equally harmful. Air contamination resulting from the burning of firewood and fuels has also been identified as a predisposing factor for development of COPD. Passive exposure to cigarette smoke may also contribute to the development of COPD. ${ }^{4}$

Cigarette smoke contains 5,000 different chemicals that are highly reactive and form a complex mixture which is not only carcinogenic but also leads to development of various chemically mediated diseases in humans. ${ }^{5}$

Chronic exposure and inhalation of toxic gases and particulate matter in tobacco smoke, triggers chronic innate and adaptive inflammatory immune response, leading to emphysematous lesions. This leads to obstruction in the small conducting airways, disruption of the epithelial barrier, interference with muco-ciliary clearance apparatus that result in accumulation of inflammatory mucous exudates in the small respiratory tract lumen. Inflammation then triggers infiltration of immune cells into the airway walls. All these immune reactions lead to depositionin connective tissue leading to narrowing of the airway wall. This leads into remodeling and repairing which causes the thickening of the airway walls, reduces lumen capacity and restricts the normal increase in caliber produced by lung inflation. This ultimately leads to airflow limitation that is the hall mark feature of COPD. ${ }^{6}$

Since prevalence of smoking is on the rise, especially among youngsters, who usually present to the clinic only after obvious clinical manifestations of COPD, screening for COPD using PFT can be helpful for early detection and primary prevention of COPD. With this in view, the current study was conducted to assess the extent of lung dysfunction in correlation with duration of smoking in young adults with no clinical features of COPD.

\section{Materials and Method}

This cross-sectional study was conducted in Department of Physiology, KVG Medical College, Sullia. The study and its conduct were cleared by ethical committee of the institute. Fifty smokers were randomly selected from population of Sullia taluk. They were smokers for a minimum of two year duration, who smoked a minimum of five cigarettes per day. The study and its aim were explained to the subjects and written informed consent was taken.

\section{Inclusion Criteria:}

1. Male subjects in age group of 18 to 30 years.

2. A minimum history of smoking tobacco for more than two year duration.

\section{Exclusion Criteria:}

1. History of cardiovascular diseases.

2. History of chronic obstructive pulmonary diseases and chronic restrictive lung diseases.

\section{Method of collection of Data:}

- Health status and duration of smoking was obtained by comprehensive Questionnaires.

- Weight was recorded with portable weighing machine

- Height was recorded using wall stadiometer.

- Computerized data logging Spiro meter for recording the pulmonary function tests (UNI-EM Spiromin 6.24.9 Ink).

Based on the duration of smoking the subjects were divided into three groups:

- Group 1 (2-4 yrs)

- Group 2(5-7 yrs)

- Group 3 (8-10 yrs).

- The lung parameters: FVC, FEV1, FEV1/FVC, $\mathrm{FEF}_{25-75 \%}$, PEFR, were recorded in all three groups. The differences among the three groups were analyzed using ANNOVA by SPSS 20 software. 


\section{Results}

Table 1: Mean lung function parameters in the three Groups

\begin{tabular}{|l|c|c|c|c|c|}
\hline Duration (Yrs) & FVC (\% P) & FEV $_{\mathbf{1}}(\mathbf{\%}$ P) & FEV $_{\mathbf{1}}$ FVC (\% P) & FEF $_{\mathbf{2 5 - 7 5} \%}(\mathbf{\%}$ P) & PEFR (\% P) \\
\hline Group 1 & $97.45 \pm 13.7$ & $102.75 \pm 13.9$ & $110.30 \pm 5.6$ & $96.40 \pm 18.8$ & $83.37 \pm 20.5$ \\
\hline Group 2 & $70.12 \pm 8.1$ & $77.24 \pm 8.3$ & $108.77 \pm 6.2$ & $96.20 \pm 12.6$ & $82.95 \pm 16.3$ \\
\hline Group 3 & $65.19 \pm 6.6$ & $73.69 \pm 7.9$ & $107.96 \pm 5.4$ & $95.87 \pm 27.3$ & $81.70 \pm 11.9$ \\
\hline
\end{tabular}

Table 2: ANNOVA

\begin{tabular}{|l|c|c|c|c|c|}
\hline & FVC & FEV1 & FEV/FVC & FEF $_{\text {25-75\% }}$ & PEFR \\
\hline F value & 49.24 & 37.82 & 0.732 & 1.585 & 0.042 \\
\hline P value & $<0.001$ & $<0.001$ & $>0.05$ & $>0.05$ & $>0.05$ \\
\hline Significance & HS & HS & NS & NS & NS \\
\hline
\end{tabular}

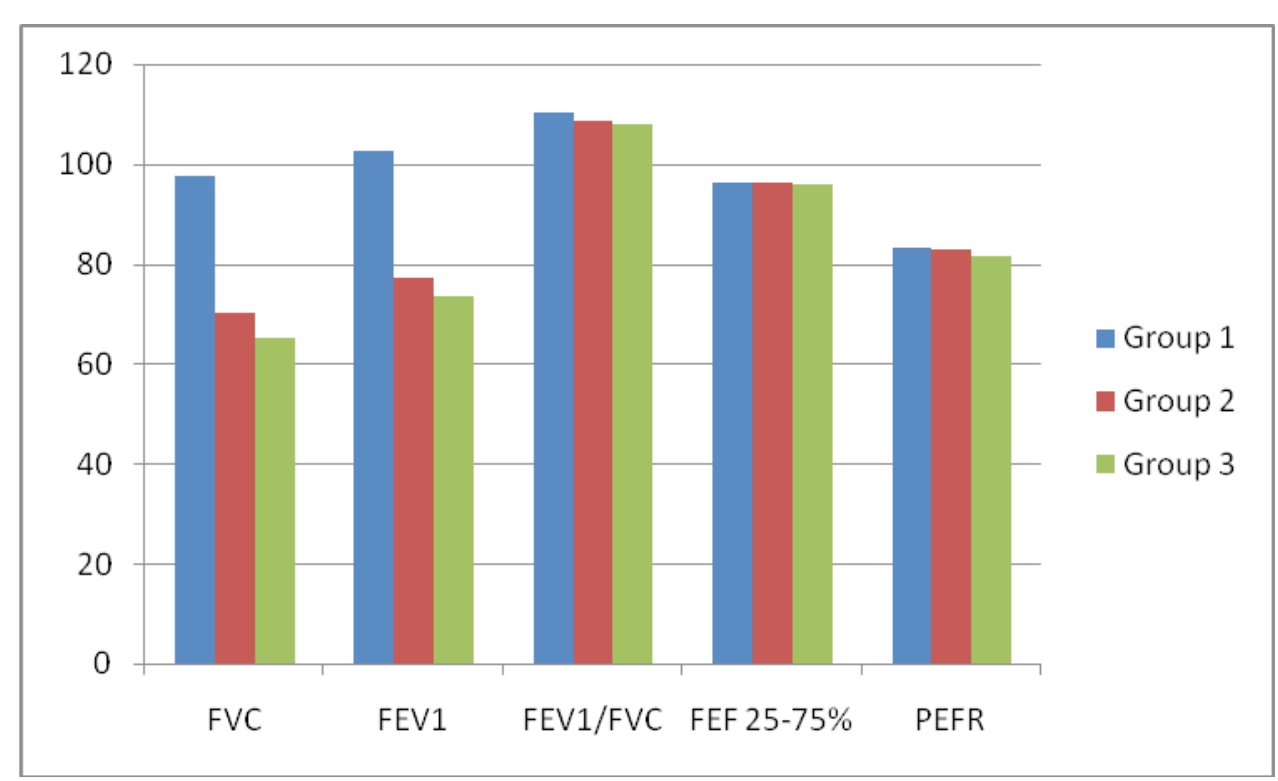

Graph 1: Mean lung function parameters in the three Groups

In the present study, analysis between the three groups for the various lung function parameters using ANNOVA, showed statistical significance for FVC ( $\mathrm{P}$ value $<0.001)$ and FEV1( $\mathrm{P}$ value $<0.001)$, however FEV1/FVC, $\mathrm{FEF}_{25-75 \%}$ and PEFR were not statistically significant $(\mathrm{P}$ value $>0.05)$.

\section{Discussion}

In the present study, smokers were classified into three groups based on the duration of smoking: Group 1 (Smokers since 2-4 years), Group 2 (Smokers since 5-7 years) and Group 3 (Smokers since 8-10 years).

The mean FVC and FEV1 in group-1 was $97.45 \pm$ 13.7 and $102.75 \pm 13.9$ (Mean $\pm \mathrm{SD}$ ) respectively, the mean FVC and FEV1 in group-2 was $70.12 \pm 8.1$ and $77.24 \pm 8.3$ (Mean \pm SD) and the mean FVC and FEV1 in group-3 was $65.19 \pm 6.6$ and 73.69 $\pm 7.9($ Mean $\pm S D)$.

The striking finding of the present study was the decline in FVC and FEV1 with duration of smoking which was statistically significant.

The results of the present study are similar to a study done by Azian Hariri et al., on university students in Malaysia, which also showed a decrease in FVC and FEV1 in smokers. ${ }^{7}$

A similar study done by Yang SC showed an irreversible decrease in FEV1 and FVC. ${ }^{8}$ 
However a similar study done in Pakistani adults by Shireen Jawed et al., showed decline in FVC, FEV1 and the FEV1/FVC ratio and also a dose response relation between history of smoking and duration of smoking. ${ }^{9}$

The significant change in FEV1 and FVC seen in the present study could be due to a host of inflammatory changes triggered by tobacco smoke in the alveoli and small airways.

To protect the lungs from injury, the respiratory tract has an elegant set of mechanisms for handling the particles and gases in inhaled air. These defenses include physical barriers, reflexes and the cough responses, the absorptive capacity of the epithelial lining, the mucociliary apparatus, alveolar macrophages and immune responses of the lung. Further high-level exposures, particularly when continued, may destroy the lung's defenses and some agents have the potential to reduce the efficacy of these defenses. Cigarette smoke contains components that impair muco-ciliary clearance and triggers inflammatory response in alveolar spaces and terminal bronchioles.

The inflammatory immune cells that infiltrate the epithelium, sub epithelium and glandular tissue include the polymorphonuclear neutrophils (PMNs), macrophages, CD8-positive (CD8+) and CD4-positive (CD4+) $\mathrm{T}$ lymphocytes and $\mathrm{B}$ cells that are part of the adaptive inflammatory immune process. This chronic inflammation, consisting of enlargement of the mucous glands and remodeling of the walls of both large and small bronchi reflects a deregulated healing process in tissue persistently damaged by the inhalation of tobacco smoke. The consequences of this process include both the development of a chronic cough and the accumulation of excess mucus in the airway's lumen. However, this inflammatory process has little influence on airflow limitation unless it extends to the small conducting airways that account for much of the increase in airway resistance..$^{10,11,12}$

The relationship between cigarette smoking and the respiratory function test of adolescents has been studied previously. Gold et al., found that FEV1/FVC decreased among adolescent smokers. Smoking habits and the number of cigarettes smoked per day were associated with the reduction in FEF25-75\%. ${ }^{13}$

However there are few studies on young people showing no apparent respiratory pathology and no advanced impairment of lung function. Indeed, the vast majority of youths demonstrated respiratory function values within the normal range. ${ }^{14}$

One of the reasons for the decrease in PFT parameters among smokers could be a decrease in functioning of respiratory muscles. Cigarette smoking affects the respiratory muscles through the influence of free radicals on the vascular system, leading to a reduction in respiratory muscle blood supply which adversely impacts respiratory function. ${ }^{15}$

Some studies showed the effect of smoking on lung function during a 12-year follow-up of new-onset asthma in adult patients. In adult-onset bronchial asthma patients cigarette smoking is widely associated with the speeding up of decline in lung function parameters. ${ }^{16}$

In contrast, some negative studies have been published, showing no relationship between smoking and lung function decline. ${ }^{17,18}$

Similar studies done showed values of different parameters of pulmonary function tests in smokers were compared with non-smokers i.e. the control group. The results showed statistically significant decrease in FVC, FEV1, FEV1/FVC ratio, PEFR, FEF25-75\% among smokers compare to non-smokers. ${ }^{19}$

Wihelmensen and Tibblin $^{20}$ have reported that the lung function tests show uniform tendency of deterioration with increasing tobacco consumption. M.S. Islam et $\mathrm{al}^{21}$ studied changes of ventilator functions among smokers and nonsmokers and observed fall in FVC amongst the smokers. Also the MEF25-75\% was markedly diminished amongst smokers.

Similarly, Burrows et al., reported that there is quantitative significant relationship between impaired ventilatory function and duration and frequency of smoking ${ }^{22}$.

However, several researchers like Angelo ${ }^{23}, \mathrm{Malo}^{24}$ and Indian workers Gupta et $\mathrm{al}^{25}$ and Mahajan et $\mathrm{al}^{26}$ observed that there was no change in FVC in smokers and nonsmokers.

In a recent study, a significant correlation was found between duration of smoking, participant age and lung function parameters (FVC, FEV1 and MVV values). These results indicate that a decrease in lung function parameters (FVC, FEV1 and MVV values) is correlated conversely with smoking duration and participant age. On the other hand, non-significant correlation was found 
between number of cigarettes smoked per day and lung function parameters (FVC, FEV1 and MVV values). ${ }^{27}$

Strength and limitation of the study: The strength of the present study was it included smokers with varying history of smoking duration, from 2 years to 10 years.

However the study was limited in the sample size. Future studies can include large sample size and provide validation to the present study.

\section{Conclusion}

In conclusion, our study showed correlation between duration of smoking and declining of all pulmonary function parameters. But the decline in FVC and FEV1 was statistically significant.

\section{Conflict of Interest: None}

Ethical Clearance: The study and its conduct were cleared by the ethical committee of the institute.

\section{Source of Funding: Self}

\section{References}

1. $\mathrm{Ng} \mathrm{M}$, Freeman MK, Fleming TD, Robinson M, Dwyer-Lindgren L, Thomson B, Wollum A, Sanman E, Wulf S, Lopez AD, Murray CJ, Gakidou E. Smoking prevalence and cigarette consumption in 187 countries, 1980-2012. JAMA 2014; 311(2):183-92.

2. Robert West. Tobacco smoking: Health impact, prevalence, correlates and interventions.Psychol health 2017 Aug 3; 32(8): 1018-1036.

3. Mannino DM, Buist AS. Global burden of COPD: risk factors, prevalence and future trends.Lancet. 2007 Sep 1; 370(9589):765-73.

4. Pauwels RA, Buist AS, Calverley PM, Jenkins CR, Hurd SS, GOLD Scientific Committee. Global strategy for the diagnosis, management and prevention of chronic obstructive pulmonary disease. NHLBI/WHO Global Initiative for Chronic Obstructive Lung Disease (GOLD) Workshop summary.Am J Respir Crit Care Med. 2001 Apr; 163(5):1256-76.

5. Talhout R, Schulz T, Florek E, van Benthem J, Wester P, Opperhuizen A. Hazardous compounds in tobacco smoke. Int J Environ Res Public Health. 2011; 8(2):613-628.

6. James C Hogg. Pathophysiology of airflow limitation in chronic obstructive pulmonary disease. The Lancet 2004; 364(9435):709-721.

7. Azian Hariri and Wan Mohd Mazdey Wan Mansor. Effects of Cigarettes Smoking on Pulmonary Function among University Students MATEC Web Conf 2017; 87:02002.

8. Yang SC. Relationship between smoking habits and lung function changes with conventional spirometry. J Formos Med Assoc 1993; 92(4):22531.

9. Shireen Jawed, Saima Ejaz and Rehana Rehman. Influence of smoking on lung functions in young adults.J Pak Med Assoc 2012; 62(8); 772-775.

10. Di Stefano A, Turato G, Maestrelli P, Mapp CE, Ruggieri MP, Roggeri A, Boschetto P, Fabbri LM, Saetta M. Airflow limitation in chronic bronchitis is associated with T-lymphocyte and macrophage infiltration in the bronchial mucosa. American Journal of Respiratory and Critical Care Medicine. 1996; 153(2):629-32.

11. O'Shaughnessy TC, Ansari TW, Barnes NC, Jeffery PK. Inflammation in bronchial biopsies of subjects with chronic bronchitis: inverse relationship of CD8+ T lymphocytes with $\mathrm{FEV}_{1}$. American Journal of Respiratory and Critical Care Medicine. 1997; 155(3):852-7.

12. Saetta M, Turato G, Facchini FM, Corbino L, Lucchini RE, Casoni G, Maestrelli P, Mapp CE, Ciaccia A, Fabbri LM. Inflammatory cells in the bronchial glands of smokers with chronic bronchitis. American Journal of Respiratory and Critical Care Medicine. 1997; 156(5):1633-9.

13. Gold DR, Wang X, Wypij D, et al.: Effects of cigaratte smoke on lung function in adolescent boys and girls. N Engl J Med, 1996, 335: 931-937.

14. AnongTantisuwat, PremtipThaveeratitham .Effects of Smoking on Chest Expansion, Lung Function and Respiratory Muscle Strength of Youths .J. Phys. Ther. Sci. 2014; 26: 167-170,

15. Ambrose JA, Barua RS: The pathophysiology of cigarette smoking and cardiovascular disease: an update. J Am Coll Cardiol, 2004, 43: 1731-1737.

16. Minna Tommola, Pinja Ilmarinen, Leena E. Tuomisto, JussiHaanpää, TerhiKankaanranta, Onni Niemelä, HannuKankaanranta. The effect of smoking on lung function: a clinical study of adultonset asthma.Eur Respir J 2016.

17. Grol MH, Gerritsen J, Vonk JM, et al. Risk factors 
for growth and decline of lung function in asthmatic individuals up to age 42 years. A 30-year followup study. Am J Respir Crit Care Med 1999; 160: 1830-1837.

18. Ulrik CS, Backer V, Dirksen A. A 10 year follow up of 180 adults with bronchial asthma: factors important for the decline in lung function. Thorax 1992; 47: 14-18

19. Anand Mistry, Rajula Tyagi, Jaydeep Kagathara, Lopa Vaidya, UrjaDholakiya, Chirag Shah. Comparative Study of Pulmonary Function Tests in Smokers and Non-Smokers.GCSMC J Med 2014;3(1).

20. Wilhelmensen L. And G. Tibblin: Tobacco smoking in fifty year old man. Respiratory symptoms and ventilatory function tests. Scand. J. Resp. Dis 1966;47: 121.

21. M.S. Islam, P.K. Dutta, D.K. Mitra and M.K. Chakraborty: Changes of ventilatory functions among smokers and non-smokers. Ind. J. Of Physiology and Pharmacology. July 1970; 14(4):165-173.
22. Burrows B, Khudson R.J, Martha Jeline, Lebowitz M.D. Quantitative relationship between cigarette smoking and ventilatory function. Amer. Review. Resp. Dis. 1977; 115:195-205.

23. Angelo MT, Silva D, Paul Hamosh. Effect of smoking cigarettes on small airways. Jour. Appl. Physio. 1973; 34(3): 361-365

24. Malo JL and Leblanc P. Functional abnormalities in young asymptomatic smokers with special references to flow volume curves. Amer. Rev. Resp. Dis 1975; 3: 623-629.

25. Gupta S and Tandon VR.: Acute effects of cigarette smoking; Jour. Asso. Physio. Of India 1977; 25:119-121.

26. Mahajan BK, Raghunandan V, Maini BK, Mahajan SK. Effect of cigarette smoking smoking on airways. 1983; 27:1-37.

27. Arwa Rawashdeh and Nedal Alnawaiseh. Effects of Cigarette Smoking and Age on Pulmonary Function Tests in $\geq 40$ Years Old Adults in Jordan. Biomedical \& Pharmacology Journal, June 2018; 11(2): 789-793. 